\title{
Study of Double-Weighted Graph Model and Optimal Path Planning for Tourist Scenic Area Oriented Intelligent Tour Guide
}

\author{
SHI Yong ${ }^{\mathrm{a}, \mathrm{b}, \mathrm{c}}$, LONG Yi ${ }^{\mathrm{a}, \mathrm{b}, *}$, WU XiaoLing ${ }^{\mathrm{a}, \mathrm{b}}$ \\ ${ }^{a}$ School of Geographic Science, Nanjing Normal University, Nanjing 210023, China \\ shiy_tz@163.com, longy@njnu.edu.cn, wuxiaolin_g@126.com \\ b MOE Key Laboratory of Virtual Geographical Environment, Nanjing 210023, China \\ ${ }^{c}$ School of Information Engineering, Nanjing Normal University Taizhou College, Taizhou 225300, China
}

Commission VI, ICWG IV/II

KEY WORDS: Path Planning, Double-Weighted Graph Model, Multi-Entrances or Exits, Travel line, Tourist Routes

\begin{abstract}
:
When tourists visiting multiple tourist scenic spots, the travel line is usually the most effective road network according to the actual tour process, and maybe the travel line is different from planned travel line. For in the field of navigation, a proposed travel line is normally generated automatically by path planning algorithm, considering the scenic spots' positions and road networks. But when a scenic spot have a certain area and have multiple entrances or exits, the traditional described mechanism of single point coordinates is difficult to reflect these own structural features. In order to solve this problem, this paper focuses on the influence on the process of path planning caused by scenic spots' own structural features such as multiple entrances or exits, and then proposes a doubleweighted Graph Model, for the weight of both vertexes and edges of proposed Model can be selected dynamically. And then discusses the model building method, and the optimal path planning algorithm based on Dijkstra algorithm and Prim algorithm. Experimental results show that the optimal planned travel line derived from the proposed model and algorithm is more reasonable, and the travelling order and distance would be further optimized.
\end{abstract}

\section{INTRODUCTION}

Traditional optimal travelling path of tourist scenic area is usually planned based on Graph Model ${ }^{[1]}$. Normally, these traditional algorithms map scenic spots (belong to some scenic area) into points of interests (POIs), and map road network links these POIs into line collection. And then construct scenic area graph model as $\mathrm{G}=(\mathrm{V}, \mathrm{E})$, with mapping POIs into vertexes (elements of collection $\mathrm{V}$ ), and mapping lines into edges (elements of collection E). And then mature algorithms in graph theories and operational researches can be used in solving path planning problem ${ }^{[2-4]}$. However, scenic area path planning is widely applied in the mobile tour guide field recently ${ }^{[5,6]}$. Actually, there may be exit significantly different between theoretical optimal paths and actual optimal paths, when only considering the scenic spots POIs with point coordinate.
As shown in figure 1 (b), scenic spot A and B are mapped as point $\mathrm{Pa}$ and $\mathrm{Pb}$ in road network, with path $\mathrm{L} 1$ is generated by traditional path planning. But when considering the inner connectivity among entrances or exits belong to scenic spot A, as shown in figure 1 (c), there would has a path L2 which is more practical and optimal between scenic spot A and B. It is obviously different between path L1 and path L2. Mainly, the reason is that the internal connectivity between entrances or exits of scenic spot A, who has changed the topology relationship of original road network and changed path planning result finally. Therefore this paper will analysis the influence of scenic spots own structural features on path planning, and then a scenic path planning model and algorithms are proposed under the consideration of multiple entrances or exits. Finally, an experiment is presented and is analysed comparatively.

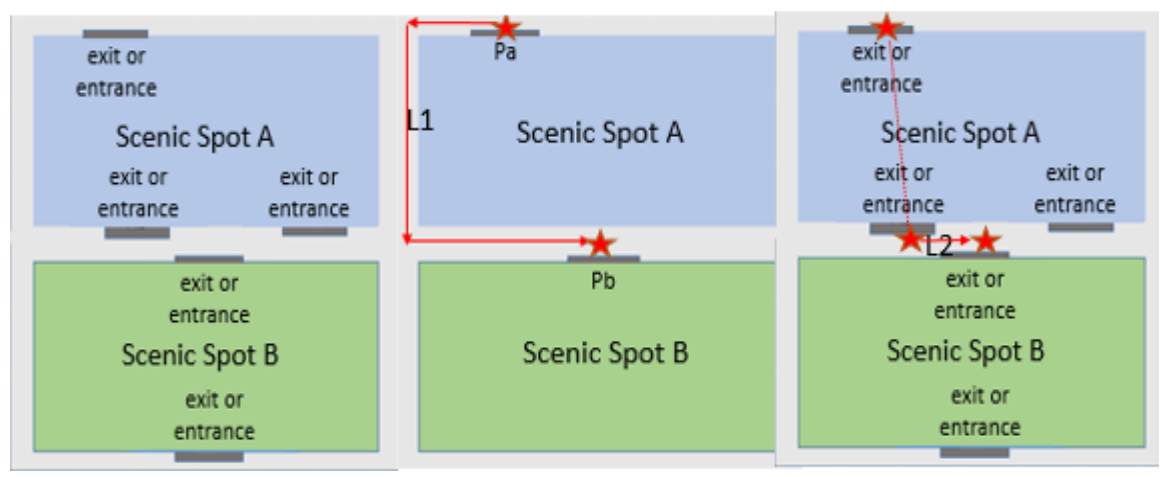

a. The basic layout of Scenic Spot $\mathbf{b}$. The traditional planned path c. The actual optimal path Fig. 1. Sketch Map of Planned Travelling Path for Scenic Spot A and B

\footnotetext{
* Corresponding author. longyi@njnu.edu.cn.
} 


\section{BASIC PRINCIPLE}

Since traditional path planning method maps scenic spots as POIs and is based on graph theory, so multiple artificial intelligence algorithms such as genetic algorithms, ant colony algorithms, multi-agent algorithms are used to solve the optimal path planning problem ${ }^{[7-9]}$. And usually people analyse the planning results from the points of recommend parts, such as travelling orders of scenic spots, travelling distance, total travelling time and so on. But for a long time, people focus on the study from the point of travelling individualization ${ }^{[10]}$, but neglects the influence of travelling orders and travelling distances. The study on the process of path planning. That is because POI without sizes and shapes, and it is relatively reasonable in consideration of the tourists' preferences and travelling autonomy and personalized needs $[1,10,11]$

But when the scenic spot has a certain area, its structural features especially its multiple entrances or exits features, would have an obviously effect on travelling order and travelling distance of the path planning. As shown in Fig 1, multiple entrances or exits allow tourists have many choices to enter or leave scenic spots in actual travelling process, and so the next scenic spot maybe multiple difference. Similarly, the more entrances or exits, the more choices tourists will get, and the more combinations of travelling order and travelling itineraries should be derived, which result in seriously difference between planned paths and actual paths, and have an influence on travel quality and guide effect. Following in table 1, we conclude the influence of multiple entrances or exits on path planning, and divide scenic spots into point of interest (POI), line of interest (LOI) and area of interest (AOI). POIs are these scenic spots without road network or with only one junction to the road network.

\begin{tabular}{|c|c|c|}
\hline $\begin{array}{c}\text { Classification } \\
\text { of Scenic Spots }\end{array}$ & $\begin{array}{c}\text { Features } \\
\text { description }\end{array}$ & $\begin{array}{l}\text { The influence on } \\
\text { the path planning }\end{array}$ \\
\hline $\begin{array}{l}\text { point of interest } \\
\text { (POI) }\end{array}$ & $\begin{array}{l}\text { without road } \\
\text { network or } \\
\text { with one } \\
\text { entrance }\end{array}$ & $\begin{array}{l}\text { One way to enter } \\
\text { or leave, and } \\
\text { would not affect } \\
\text { choice of next spot }\end{array}$ \\
\hline $\begin{array}{l}\text { line of interest } \\
\quad(\mathrm{LOI})\end{array}$ & $\begin{array}{l}\text { with two } \\
\text { entrances or } \\
\text { exits }\end{array}$ & $\begin{array}{c}\text { Two kinds of } \\
\text { way to enter or } \\
\text { leave, and would } \\
\text { affect choice of } \\
\text { next spot }\end{array}$ \\
\hline $\begin{array}{l}\text { area of interest } \\
(\mathrm{AOI})\end{array}$ & $\begin{array}{l}\text { with more } \\
\text { than two } \\
\text { entrances or } \\
\text { exits }\end{array}$ & $\begin{array}{l}\text { Multiple ways to } \\
\text { enter or leave, and } \\
\text { would affect } \\
\text { choice of next spot }\end{array}$ \\
\hline
\end{tabular}

Tab.1 Influence of Scenic Spots' Topology on Path Planning
Obviously, optimal path planning considering multiple entrances or exits structural features would be similar to actual travelling, and be more refined than traditional path planning. Therefore, a Double-weighted Graph Model is proposed based on considering structural feature of multiple entrances or exits, and optimal path planning algorithm is discussed as followed.

\section{DOUBLE-WEIGHTED GRAPH MODEL}

Based on the traditional graph model, double-weighted graph model can be dynamically selected and so reflect the influence of scenic spots own structural feature on path planning. For example the vertex's position coordinate can be one of the scenic spot's entrances or exits, and on the same time the distance between these vertexes would be changed. Through this model, can improve traditional path planning mode whose vertexes are fixed and weights of edges are changeable. And the following is the definition of double-weighted graph model.

Definition 1: define scenic spot model as follow:

$$
\left\{\begin{array}{c}
S=\left(S^{\prime}, T S\right) \\
S^{\prime}=\{\mathrm{si} \mid \mathrm{i}=1,2, \ldots, \mathrm{n}\}
\end{array}\right.
$$

Define $S^{\prime}$ as the collection of scenic spot's entrances or exits, and TS is the recommend travelling time. Where $\mathrm{n}$ is the total number of scenic spots' entrances or exits, "si" as one of entrances or exits belong to scenic spot $\mathrm{S}$.

Definition 2: define graph model of scenic area as follow:

$$
\left\{\begin{array}{l}
\mathrm{G}=(\mathrm{V}, \mathrm{E}) \\
\mathrm{V}=\left\{S i^{\prime} \mid i=1,2, \ldots, m\right\} \\
\mathrm{E}=\left\{(s k x, \text { sjy }) \mid s k x \in S k^{\prime}, s j y \in S j^{\prime}\right\}
\end{array}\right.
$$

Define $\mathrm{V}$ as vertexes collection, $\mathrm{E}$ as edges collection. Where $\mathrm{m}$ is the total number of scenic spots, define $\mathrm{Si}^{\prime}$ as scenic spot model according to definition 1 , and define (skx, sjy) as the edge from skx to sjy, where skx means the no. $x$ entrance or exit of scenic spot Sk, and the same to sjy.

From the definition 2, the double-weighted graph model of scenic spot can be seen as a complex graph, for its vertexes collection consists of entrances or exits belong to some scenic spot.

Definition 3: define the weight function $f((S k, S j))$ for edge, to determine the nearest line between Vertex $\mathrm{Sk}$ and $\mathrm{Sj}$. In the (f1), function dis (skx, sjy) is to find the shortest distance from vertex skx to sjy based on Dijkstra algorithm. Function min $(\{\})$ is to find the minimum edge (skx, sjy) in the collection, and function cou $(\{\})$ is to count the number of elements in the collection. Define V' is as collection of entrances or exits which had been visited, and define $\mathrm{N}$ is as collection of scenic spot which is needed to be visited, and define $T$ is as collection consists of passed scenic spots.

$$
f((S k, S j))=\left\{\begin{array}{l}
\text { TSk } \mathrm{k}=\mathrm{j}, \quad S k \notin \mathrm{V}, \quad \mathrm{sk} \in N \\
\min \left(\left\{\operatorname{dis}(\mathrm{skx}, \quad \mathrm{sjy}) \mid x, y=1,2, \ldots, \operatorname{count}\left(S k^{\prime}\right)\right\}\right) \mathrm{k}=\mathrm{j}, \mathrm{Sk} \in T \\
\min \left(\left\{\operatorname{dis}(\mathrm{skx}, \operatorname{sjy}) \mid x=1,2, \ldots, \operatorname{cou}\left(S k^{\prime}\right), y=1,2, \ldots, \operatorname{cou}\left(S j^{\prime}\right)\right\}\right) \mathrm{k} \neq \mathrm{j}, \mathrm{skx} \notin \mathrm{V}^{\prime}, \quad S k \in N \\
\min \left(\left\{\operatorname{dis}(\operatorname{skx}, \operatorname{sjy}) \mid x=1,2, \ldots, \operatorname{cou}\left(S k^{\prime}\right), y=1,2, \ldots, \operatorname{cou}\left(S j^{\prime}\right)\right\}\right) \mathrm{k} \neq \mathrm{j}, \mathrm{vkx} \in \mathrm{V}^{\prime}, \quad S k \in T \\
\infty \exists \operatorname{spz} \in S p^{\prime}, \text { and } f((S k, S j))=f((S k, S p))+f((S p, S j))
\end{array}\right.
$$

Definition 4: define the weight function $f^{\prime}\left(\left(s, S i^{\prime}\right)\right)$ for entering vertexes (scenic spots), to determine the nearest entrance or exit to entering another scenic spot. In the (f2), s means the location of current start point or a determined leaving point, $\mathrm{Si}^{\prime}$ as scenic spot model according to definition 1, Siy means the entrances or exits belong to scenic spot Si. Definitions of function $\operatorname{dis}(\mathrm{s}, \mathrm{Sjy}), \min (\{\})$ and function cou $(\{\})$ are accroding to (f1). 


$$
f^{\prime}\left(\left(s, S i^{\prime}\right)\right)=\min \left(\left\{\operatorname{dis}(\mathrm{s}, \mathrm{Six}) \mid \mathrm{y}=1,2, \ldots, \operatorname{cou}\left(\mathrm{Si}^{\prime}\right)\right\}\right)
$$

Definition 5: define the weight function $f^{\prime \prime}\left(\left(S i^{\prime}, \mathrm{Sj}^{\prime}\right)\right)$ for leaving vertexes (scenic spots), to determine the optimal entrance or exit to left current scenic spot. In function (f3), $S i^{\prime}, \mathrm{Sj}^{\prime}$ as scenic spot according to definition 1, definitions of function dis(s, $\mathrm{Sjy}), \min (\{\})$ and function cou ( \{\}$)$ are according to (f1).

$$
\begin{aligned}
& f^{\prime \prime}\left(\left(\operatorname{Si}^{\prime}, \mathrm{Sj}^{\prime}\right)\right)=\min (\{\operatorname{dis}(\operatorname{Six}, \operatorname{Sjy})\}) \\
& \text { Where } \mathrm{x}=1,2, \ldots, \operatorname{cou}\left(\mathrm{Si}^{\prime}\right) \\
& \qquad \begin{aligned}
\mathrm{y} & =1,2, \ldots, \operatorname{cou}\left(\mathrm{Sj}^{\prime}\right) \\
\mathrm{y} & \neq f^{\prime}\left(\left(s, S i^{\prime}\right)\right), \mathrm{s} \text { as the entering point. }
\end{aligned}
\end{aligned}
$$

Definition 6: define $\mathrm{R}$ as optimal path as follow:

$$
\left\{\begin{array}{l}
\mathrm{R}=\left(\mathrm{V}^{\prime}, \mathrm{P}, \mathrm{C}\right) \\
V^{\prime}=\{S k x \mid k=1,2, \ldots, m, x=1,2, \ldots, n\} \\
\mathrm{P}=\{s, \text { Skx }, \mathrm{TSk}, \text { Sky }, \ldots, \text { Sjo, Sjp }, \mathrm{t}\} \\
C=\sum_{k=1}^{n} T S k+\sum_{k, j=1}^{n} f((S k, S j))
\end{array}\right.
$$

In definition (d3), according to (f3), $\mathrm{V}^{\prime}$ is as collection of entrances or exits which had been visited. $P$ means the order of travelling vertexes, point $\mathrm{s}$ and point $\mathrm{t}$ means the start and end point for current travel. Skx,TSk,Sky represent that people travel scenic spot Sk with starting from entrance $\mathrm{x}$ and leaving from entrance $y, S j o, S j p$ represent that people pass by the entrance $\mathrm{o}$ and $\mathrm{p}$ belong to scenic spot $\mathrm{Sj}$. And define $\mathrm{C}$ is the total cost consist of travelling time and travelling distance.

\section{ANALYSIS OF OPTIMAL PATH PLANNING}

Based on double-weighted graph model, this paper proposed algorithms for optimum path planning, which include methods both of building graph of scenic spot and path planning.

\subsection{Algorithm of building graph of scenic spot}

As actual graph model of scenic spot is not a complete graph, and before the process of optimization, the double-weight graph model of scenic spot according to (d2) should be simplified, the algorithm procedure as shown in fig 2 .

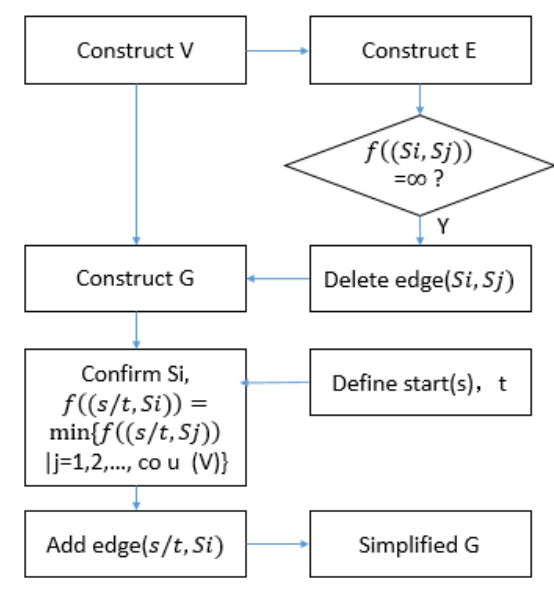

Fig.2 Building Procedure of Scenic Graph

In Fig. 2, the algorithm procedure step as follows:
Step (1): firstly, to determine the location of scenic spots and their own entrances or exits, then construct collection $\mathrm{V}$ of vertexes according definition (d1) and (d2).

Step (2): to construct set $\mathrm{E}$ of edges according to set $\mathrm{V}$ and definition (d2).

Step (3): to delete edges that is not directly associated with each other by finding whose weight is $\infty$, to construct graph model $\mathrm{G}$ of scenic spots according to function (f1).

Step (4) to add the start point $s$ and end point $t$ to this travel plan.

Step (5) to add edge (s, Si) and edge (t, sj) according to function (f2), algorithm is over.

\subsection{Algorithm of optimal path planning}

Based on building the graph $\mathrm{G}$ of scenic spot, and on the basis of Dijkstra algorithms and Prim algorithms, an algorithm of optimal path planning according to the double-weight graph model of scenic spot is proposed as follows:

Step (1): to initialize, according to definition (d3), set collection $\mathrm{V}^{\prime}$ as empty, and set $\mathrm{P}=\{\mathrm{s}\}$ as path, and define s represent the current determined point, define collection $\mathrm{Vt}$ consist of scenic spots which directly link to $s$.

Step (2): if Vt is not empty, clear it and calculate the elements belong to Vt. For each scenic spot $\mathrm{Si}$ ( $\mathrm{Si} \in \mathrm{Vt}$ and $\mathrm{Si} \notin \mathrm{V}^{\prime}$ ), according to function (f2), determine the result of entering entrance or exit Sij and put Si to collection V' and put Sij into collection $\mathrm{P}$ at last place. If TSi $\notin \mathrm{P}$, then put TSi into set $\mathrm{P}$ at last place, and then go to step (3). Otherwise, set $\mathrm{s}=\mathrm{Sij}$, and repeat executing step (2).

Step (3): for each scenic spot $\operatorname{Sm}\left(\operatorname{Sm} \in V\right.$ and $\left.\operatorname{Sm} \notin V^{\prime}\right)$, according to function (f3), determine the result of leaving entrance or exit Sik, then put Sik to set V', and then set s = Sik.

Step (4): repeat step (2) and (3) until collection P contain all scenic spots.

Step (5): get the shortest path from current point $s$ to $t$ and add the location of passed entrances to set $\mathrm{P}$, algorithm is over.

\section{EXPERIMENT AND ANALYSIS}

\subsection{Basic Condition of Experiment Area}

Taking ShangHu Lake Park as experiment area, and its remotesensing image is shown in Fig. 3.

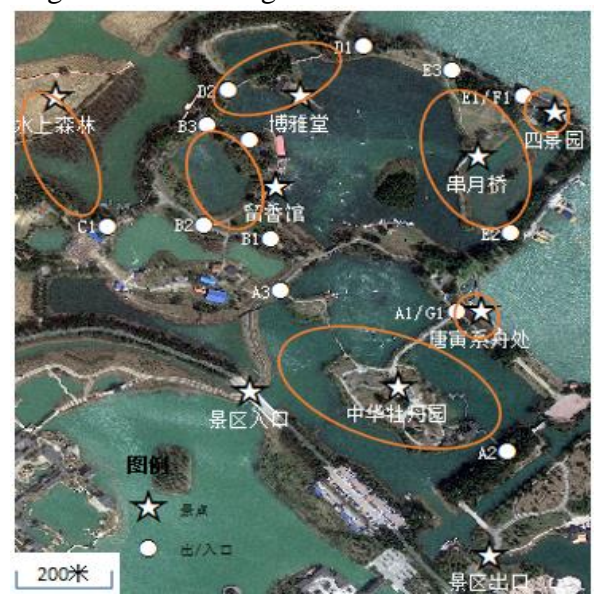

Fig. 3 Remote-sensing Image of Experiment Area 
As shown in Fig.3, the experiment area includes seven scenic spots, which are marked by circles. The basic condition of experiment area and the serial number of entrance or exit are shown in Fig3 and Tab2.

\begin{tabular}{|c|c|c|c|}
\hline $\begin{array}{l}\text { Scenic spot } \\
\text { name }\end{array}$ & $\begin{array}{c}\text { Id of } \\
\text { Scenic } \\
\text { spot }\end{array}$ & $\begin{array}{l}\text { serial number } \\
\text { of exit or } \\
\text { entrance }\end{array}$ & $\begin{array}{l}\text { Scenic spot } \\
\text { type }\end{array}$ \\
\hline Peony Park & $\mathrm{A}$ & $\mathrm{A}_{1}, \mathrm{~A}_{2}, \mathrm{~A}_{3}$ & AOI \\
\hline $\begin{array}{c}\text { Liuxiang } \\
\text { Exhibition Hall }\end{array}$ & B & $\mathrm{B}_{1}, \mathrm{~B}_{2}, \mathrm{~B}_{3}$ & AOI \\
\hline $\begin{array}{l}\text { Forest on } \\
\text { Water }\end{array}$ & C & $\mathrm{C} 1$ & POI \\
\hline $\begin{array}{c}\text { Boya Palace } \\
\text { Hall }\end{array}$ & D & $\mathrm{D}_{1}, \mathrm{D}_{2}$ & LOI \\
\hline $\begin{array}{l}\text { Chuanyue } \\
\text { Bridge }\end{array}$ & E & $\mathrm{E}_{1}, \mathrm{E}_{2}, \mathrm{E}_{3}$ & AOI \\
\hline $\begin{array}{c}\text { Four Season } \\
\text { Park }\end{array}$ & $\mathrm{F}$ & $\mathrm{F} 1(=\mathrm{E} 1)$ & POI \\
\hline $\begin{array}{c}\text { TANGYin } \\
\text { Anchor Spot }\end{array}$ & G & $\mathrm{G} 1(=\mathrm{A} 1)$ & POI \\
\hline
\end{tabular}

Tab2. Information of Experiment Area

\subsection{Experiment Content}

\subsubsection{Comparison of Traditional Scenic Spot Graph Model and Double-weighted Graph Model}

According to definition (d1), (d2) and construction algorithm of traditional scenic spot graph, the Double-weighted graph model is built as shown in Fig. 4(b). In order to compare more easily and clearly, taking A3, B1, C1, D2, E3, F1, G1 as the mapping vertexes of traditional scenic spot model, taking the connection line of two directly related vertex as edge, and taking the construction algorithm proposed in this article, traditional scenic spot graph model is built as shown in Fig. 4(a). For traditional scenic spot graph model takes only one exit or entrance into consideration, so traditional scenic spot graph model can be seen as special case of double-weight model in this article, and construction algorithm in chapter 4.1 can be seen universal.

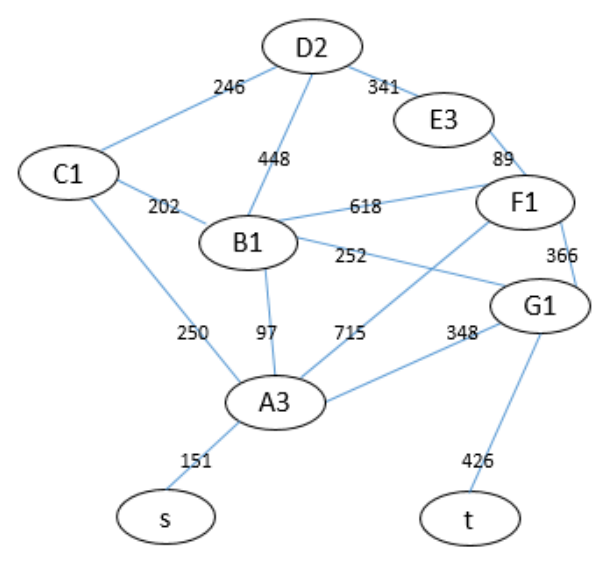

Fig. 4 (a) Traditional Scenic Spot Graph Model

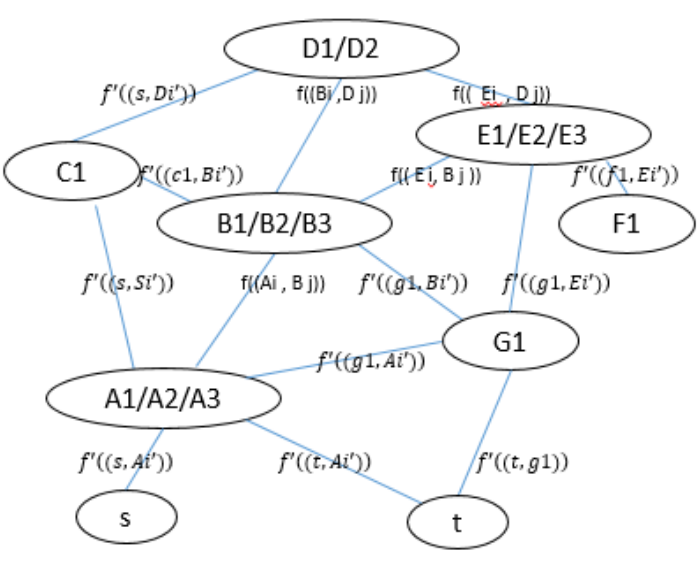

Fig. 4 (b) Scenic Spot Double-weighted Graph Model

As shown in Fig. 4, both traditional scenic spot model and double-weighted model are not complete graph, which expressing the vertexes of the actual relationship between scenic spots. And the traditional model usually sets its vertexes fixed, and sets its edges can be selected by distance as weight, which can be seen in Fig. 4(a) the built model with single vertex and fixed distance. While double-weighted model sets both its vertexes and edges can be selected by weighting function, which can be seen in Fig. 4(b), the built model with multiple vertex and weighted distance. In Fig. 4-b, vertex F1 as an hanging point, shows that in scenic spot double-weighted graph model, scenic spot F located on the path which constructed by exits or entrances points of scenic spot $\mathrm{E}$.

\subsubsection{Comparison of Optimal Planned Route}

In order to show the advantages of double-weighted graph model, this article splits optimal planned path into two parts as tour guide path and tour return path, in which the guide path is the chaining route between scenic spots for visitors visiting, while the return path is the optimal path guiding to the exit of the scenic spot after the visitor has travelled all the scenic spots. Through analysing on the points of guide path and return path, we make comprehensive comparison in terms of the order and plan distance of the path planning.

Based on traditional model and double-weighted model as shown in Fig.4 (a) and (b), taking the proposed optimal planning algorithm in chapter 4.2. Firstly, as shown in Fig. 5, we compare the result of optimal route planned from entrance s to exit $t$.Secondly, as shown in Fig. 6, we compare the result of optimal route planning from exit to entrance $s$. Where can be seen different optimal paths consists of different guide path and return path.

And in Fig. 5 and Fig. 6, vertex symbol "A3>A1,A3,A2" in double-weighted model means that:(1)Optimal planned route recommends to tour scenic spot A through entering at entrance A3 and leaving at entrance A1. (2) In the procession of following touring guide, scenic spot A is not toured, entrance A3, A3 have been passed by. 


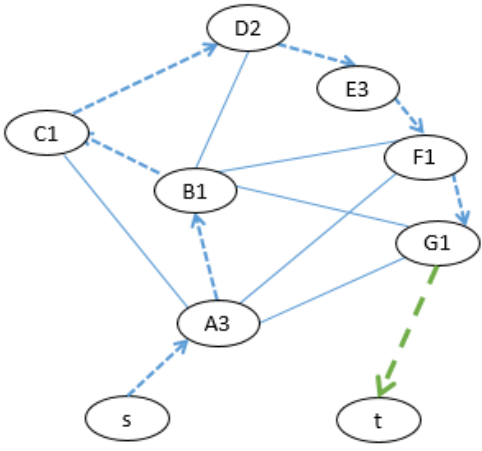

(a)

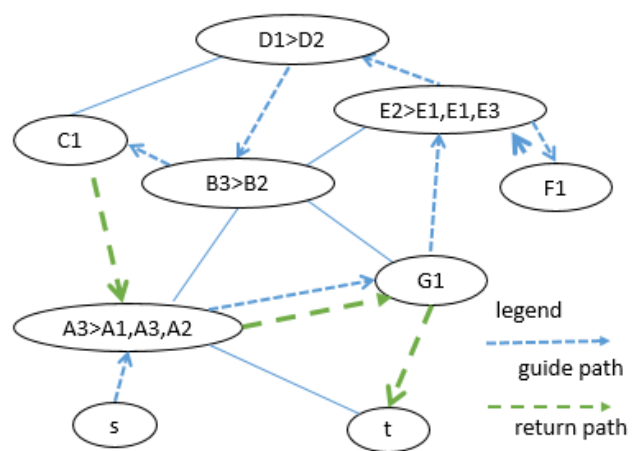

(b)

Fig. 5 Contrastive Analysis of Optimal Path from s to t

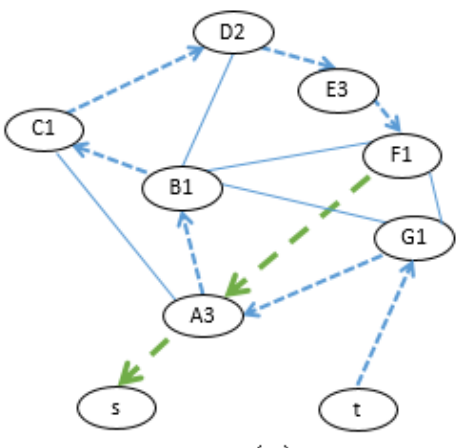

(a)

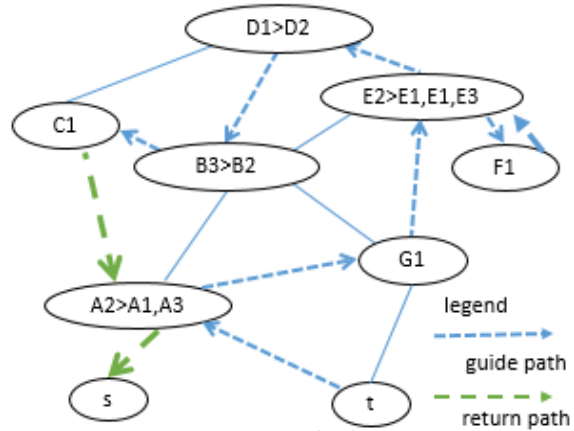

(b)

Fig. 6 Contrastive Analysis of Optimal Path from t to s

According to definition (d3), comprehensive comparison of the optimal planned route is shown in Tab. 3. The table domains consists of Path Direction, Graph Model, Planned Path, Planed distance and a short analysis. What's more, domain planned Route can represent travelling order, and domain Planned
Distance can represent traveling time. Analysis shows that double-weight graph model leads a difference travelling order, and leads a much shorter travelling distance, and leads an obvious lessening on guide path distance.

\begin{tabular}{|c|c|c|c|c|}
\hline Path Direction & Graph Model & Planned Route & Planned Distance & Analysis \\
\hline \multirow[t]{2}{*}{ From $\mathrm{s}$ to $\mathrm{t}$} & traditional model & $\begin{array}{l}\text { s,A3,TA,B1,TB,C1,TC,D2,TD,E3,T } \\
\text { E,F1,TF,G1,TG,t }\end{array}$ & $\begin{array}{l}\text { total } 1918 \mathrm{~m} \text { with } \\
\text { guide path } 1492 \mathrm{~m} \text {, } \\
\text { return path } 426 \mathrm{~m}\end{array}$ & $\begin{array}{l}\text { proposed model leads a } \\
\text { difference planned travelling } \\
\text { order, reduces total distance }\end{array}$ \\
\hline & proposed model & $\begin{array}{l}\text { s,A3,TA,A1,G1,TG,E2,TE,E1,TF,E2, } \\
\text { D2,TD,D1,B3,TB,B2,C1,TC,A3,G1,t }\end{array}$ & $\begin{array}{l}\text { total } 1512 \mathrm{~m} \text { with } \\
\text { guide path } 586 \mathrm{~m} \text {, } \\
\text { return path } 926 \mathrm{~m}\end{array}$ & $406 \mathrm{~m}$ \\
\hline \multirow[t]{2}{*}{ From $\mathrm{t}$ to $\mathrm{s}$} & traditional model & $\begin{array}{l}\text { t,G1,TG,F1,TF,E3,TE,D2,TD,C1,TC, } \\
\text { B1,TB,A3,TA,A3,s }\end{array}$ & $\begin{array}{l}\text { total } 1918 \mathrm{~m} \text { with } \\
\text { guide path } 1767 \mathrm{~m} \text {, } \\
\text { return path } 151 \mathrm{~m}\end{array}$ & $\begin{array}{l}\text { proposed model leads a } \\
\text { difference planned travelling } \\
\text { order, reduces total distance }\end{array}$ \\
\hline & proposed model & $\begin{array}{l}\text { t,A2,TA,A1,G1,TG,E2,TE,F1,TF,E3, } \\
\text { D2,TD,D1,B3, TB,B2,C1,TC,A3,s }\end{array}$ & $\begin{array}{l}\text { total } 1060 \mathrm{~m} \text { with } \\
\text { guide path } 659 \mathrm{~m} \text {, } \\
\text { return path } 401 \mathrm{~m}\end{array}$ & $858 \mathrm{~m}$ \\
\hline
\end{tabular}

Tab. 3. Results of Path Planning of Experiment Area

\subsection{Analysis of experiment result}

(1) As shown in Fig. 5 , Fig. 6 and Tab. 3, considering the information of scenic spots' entrances or exits, in the condition of same starting and ending point, comparing with traditional graphic model of scenic area, optimal path that gets from Double-Weighted Graph Model has an obvious difference in the planned order.
(2) As shown in Table3, in the process of optimal planning, Double-Weighted Graph Model reduces planned path distance effectively, but with a disadvantage of longer returning path. Which means that there has a shortest distance in guide route. Based on proposed algorithm, through the analysis of guide route and return route, we can arrange tour process reasonable and serve visitors' planning better. 
(3)Traditional graphic model can be seen as a special case when the scenic spot has only one entrance or exit in Double-Weighted Graph Model. Because the total number of entrances or exit is limited, so the time-complexity of proposed algorithms is limited to $\mathrm{O}\left(\mathrm{n}^{3}\right)$.

\section{CONCLUSION}

In this paper, we have analysed the influence on path planning from scenic spots' structural features, and proposed a doubleweight graph model in which the weight both of vertexes and edges can be dynamically selected, and then the algorithms of building graph of scenic spot and optimal path planning are given. An analysis shows that optimal path planning based on doubleweight graph model can reduce travel distance effectively. The planning result is more close to actually travel process, which proves that the double-weight graph model have enough ability to serve individual path planning.

However, only road distance between vertexes as weight is discussed in our double-weight graph model. In the future study, a comprehensive weight calculation model will be studied by considering not only tourist preferences and scenic spots own characteristics such as classifications and popularity, but also real-time tourist flow and dynamic traffic conditions in scenic spots. The final purpose allows achievements in this paper can be fully used in fine service for scenic spots.

\section{Acknowledgements}

This work was supported in part by by the National Natural Science Foundation of China under Grant No.41301144, and the Changshu Overseas Talents Program under Grant No.CRRC1130, and the Jiangsu QinLan Project (2010).

\section{REFERENCES}

[1] HU Junguo, DONG Feng, QI Hengnian. Study on The Path Planning of Tourist Scenic Area based on BVC Ant Colony Algorithm[C].2010 International Symposium on Computational Intelligence and Design: 18-22.

[2] FANG Dong-yun. The application of graphic theory in tourist routes seletcion [J]. Journal of Changchun University of Technology (Natural Science Edition).Oct.2009: 582-596.

[3] SHI Xiao-yi. Optimal design of tourist routes [J]. Journal of Chongqing University of Arts and Sciences (Natural Science Edition). Feb., 2012:9-14.

[4] ZOU Shi-lin, Ruan Jian, in Bo. The application of the shortest path algorithm in the tourist route planning-With $\mathrm{M} \mathrm{t}$ LuShan as an example [J]. Science of Surveying and Mapping, Sep., 2008:109-192.

[5] WANG Su, DU Jun-ping, GAO Tian. Study and Realization of multimedia intelligent tourism navigation system [J]. Journal of Central South University (Science and Technology). Sep.2009: 335-340.

[6] Gavalas, Damianos, Mytilene .Personalized routes for mobile tourism[C].Wireless and Mobile Computing, Networking and Communications (WiMob), 2011 IEEE 7th International Conference, 295-300.

[7] LU Qing, LIANG Chang-yong, HUANG Yong-qing. Interactive multi-agent genetic algorithm for travel itinerary planning $[\mathrm{J}]$. Application Research of Computers, Nov. 2008:3311-3313

[8] Zhong Weicai, Xue Mingzhi, Liu Jing. Multi-Agent Genetic Algorithm Based on ARE-Model G E N E T I C A L G O R I T H M [J]. PR \&AI, Dece. 2003:309-396.

[9] RoySenjuti Basu,Das Gautam,Amer-Yahia, S.Interactive itinerary planning[C].Data Engineering (ICDE), 2011 IEEE 27th International Conference on. 11-16 April 2011:15-26.

[10] ZHANG Yanjun, XU Kelin. Personalized tourist trip design with multi-objective of group members based on fuzzy adaptive and polymorphic ant colony algorithm [J]. Computer Engineering and Applications, 2012, 48. (35): 207-212.

[11] Rodríguez B, Molina J, Pérez F, et al. Interactive design of personalized tourism routes [J]. Tourism Management, 2011, 33 (4): 926-940. 